\title{
AVALIAÇÃO DE DESEMPENHO ESTRUTURAL DE PAINÉIS DE CONCRETO ARMADO PRÉ-FABRICADOS
}

\author{
L. S. LORENZI, A. LORENZI, D. L. KLEIN \\ Laboratório de Ensaios e Modelos Estruturais - LEME, Escola de Engenharia, Porto Alegre - RS - Brasil
}

\section{RESUMO}

A atual demanda por produtividade no setor da construção civil brasileira induz a utilização de sistemas construtivos mais ágeis na sua construção às edificações; dentre os sistemas mais utilizados estão os painéis de concreto armado pré-fabricados. Outro fato relevante no cenário da construção civil brasileira é o atendimento da norma ABNT NBR 15575/2013 (Norma de Desempenho de Edificações, onde estabelece requisitos e critérios de desempenho quanto a área de segurança, habitabilidade $\mathrm{e}$ sustentabilidade. Este artigo apresenta a avaliação de desempenho estrutural de edificações habitacionais que utilizam painéis de concreto armado pré-fabricados na composição das fachadas e tem como objetivo o analisar o desempenho estrutural da fachada, especificamente a fixação entre o painel e a laje. O método de avaliação de desempenho estrutural utilizado foi o de ensaios experimentais em laboratório e em campo, contemplando o Estado Limite de Serviço (ELS), Estado Limite Último (ELU), onde empregou-se ensaios que simulam situações de uso e operação das fachadas da edificação. O resultado da avaliação de desempenho estrutural apresentou-se satisfatório. Concluiu-se que os painéis de concreto armado atendem as especificações e que a realização desses ensaios oportuniza o conhecimento prévio do comportamento em uso dos painéis ao longo da vida útil da edificação.

Palavras clave: Desempenho Estrutural; Fachadas; Concreto Armado.

\begin{abstract}
The current demand for productivity in the Brazilian construction sector induces the use of more faster building systems in their construction to buildings. Among the most widely used systems are prefabricated reinforced concrete panels. Another relevant fact in the Brazilian civil construction scenario is the compliance with ABNT NBR 15575/2013 (Building Performance Standard), which establishes requirements and performance criteria regarding safety, habitability and sustainability. This paper shows the structural performance of residential buildings that use prefabricated reinforced concrete panels in the composition of facades. The aim is to analyze the structural performance of the facade, specifically the fixation between the panel and the slab. Experimental tests in the laboratory and in the field where test to simulate use and operation situations of building façades. It was concluded that the reinforced concrete panels attend the specifications and that the performance of these tests allows the prior knowledge of behavior in use of this panels through the useful life of the building.
\end{abstract}

Keywords: Structural performance; Facades; Reinforced concrete. 


\section{INTRODUÇÃO}

A construção civil brasileira encontra-se num período de grandes transformações. A produtividade é alvo de todas as empresas que estão no mercado, onde priorizam a realização de edificações em curto espaço de tempo e com qualidade. Diante disso, estão os sistemas construtivos em concreto armado pré-fabricado que possuem racionalidade e controle tecnológico mais apurados que os sistemas construtivos convencionais.

$\mathrm{Na}$ área tecnológica, com especial atenção a incorporação de novos materiais às edificações habitacionais. A homologação da ABNT NBR 15.575 (2013) - Norma de Desempenho - está promovendo mudanças significativas na indústria da construção civil, como, por exemplo, sendo mais criteriosa nos processos para concepção e construção da edificação habitacional e demonstrando um maior comprometimento com a qualidade final da mesma; cenário antes não visto no Brasil.

Uma das principais contribuições da entrada em vigência da Norma de Desempenho está na aplicação do conceito de desempenho na fase de fabricação dos componentes, projeto, construção e uso, operação e manutenção. Esse comportamento está fazendo com que a cadeia da indústria da construção civil esteja mais atenda às necessidades dos profissionais da área e investindo mais esforços para obter e transmitir informações dos produtos com foco no desempenho.

A aplicação do conceito de desempenho nos projetos de edificações habitacionais no Brasil é recente. A grande maioria dos sistemas construtivos, tradicionais e inovadores, utilizados em edifícios residenciais não incorporavam em seus projetos itens de desempenho. Segundo Silva (2011) uma das razões para isso pode estar na falta de conscientização dos profissionais para o desempenho de produtos, confundindo a visibilidade de uma marca ou a tradição de uma empresa com a qualidade oferecida.

Visando analisar o desempenho estrutural dos painéis de concreto armado pré-fabricados utilizados em fachadas de edificações em altura, o presente artigo apresenta o resultado de ensaios que comprovam o comportamento da fachada durante a vida útil. A avaliação de desempenho estrutural proporciona o conhecimento do comportamento em uso da fachada, visto que os ensaios utilizados têm métodos que se aproximam do uso dos painéis, simulando esforços e cargas que os mesmos serão submetidos em uso.

\section{DESCRIÇÃO DOS PAINEÍS}

O painel de concreto armado pré-fabricado é constituído por dois tipos de concreto: cinza e branco (arquitetônico), ambos com tensão característica de fck $\geq 30$ Mpa e tem dimensões (variável x $2790 \mathrm{x}$ 100) $\mathrm{mm}$, comprimento, altura e espessura, respectivamente. A Figura 1(a) apresenta o desenho esquemático da forma de fixação na parte inferior do painel e Figura 1(b) apresenta os corpos de prova para o ensaio.

Para a representação do painel e fixação na laje foram montados 3 (três) corpos de prova representativos de como é realizada a fixação dos painéis na laje para o ensaio de compressão centrada com inserto metálico (Figura 2), cujas características estão indicadas a seguir:

- Os corpos de prova (CPs) são compostos pelo encontro entre o painel e uma secção de laje, que representa a fachada fixada na laje.

- Os corpos de prova (CPs) são compostos de painéis de concreto armado pré-fabricados (500 x 1000 x 100) mm, comprimento, altura e espessura, respectivamente, e insertos metálicos de aço patinado. 


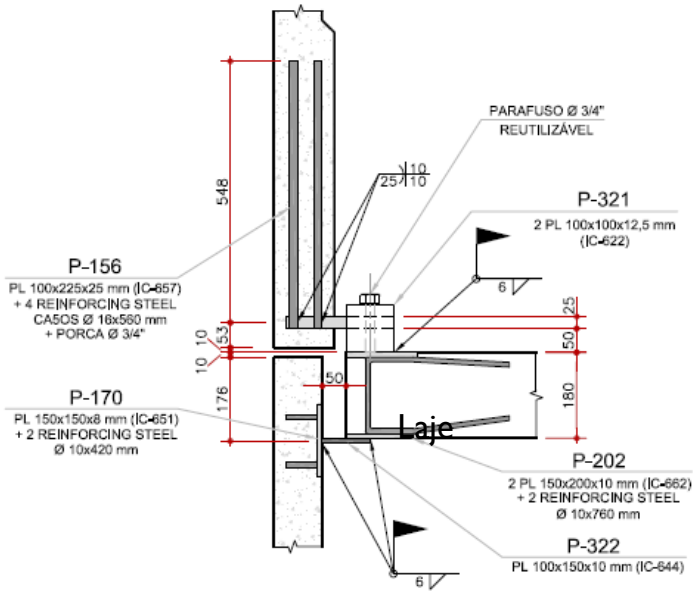

(a)

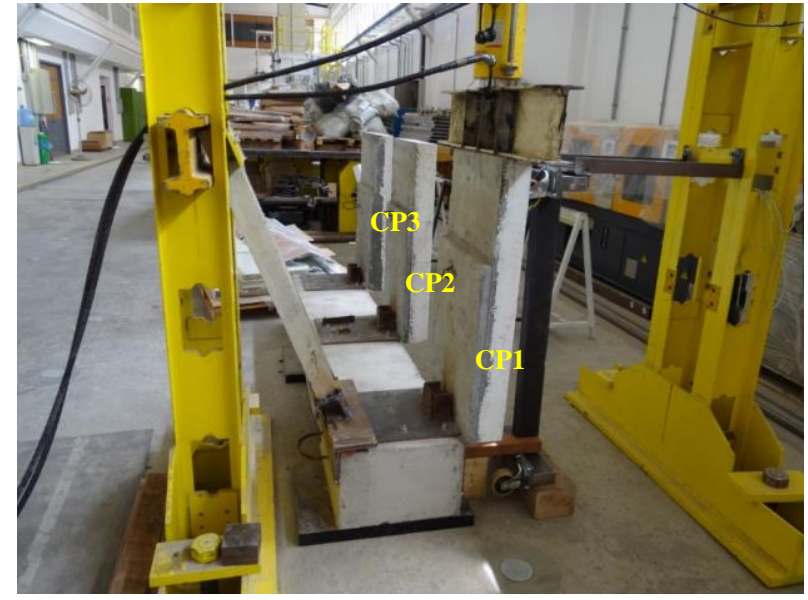

(b)

Figura 1: (a) Desenho esquemático do painel e detalhe da fixação do painel na laje, parte inferior e (b) detalhe do CP1, CP2 e CP3 com os dois tipos de concreto no painel e fixação, com solda, no inserto metálico.

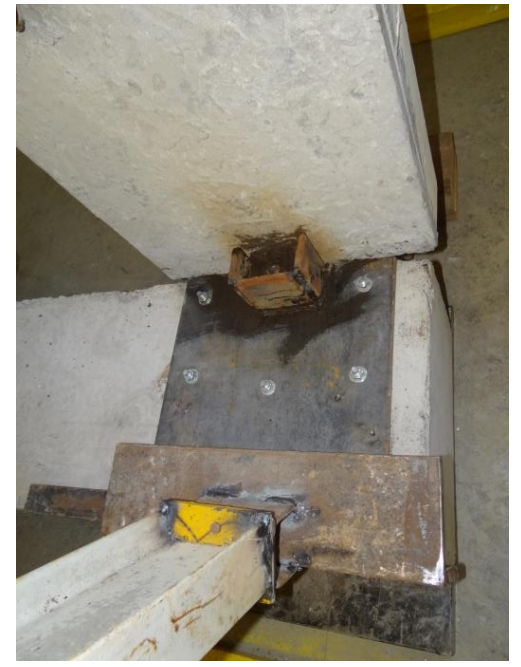

(a)

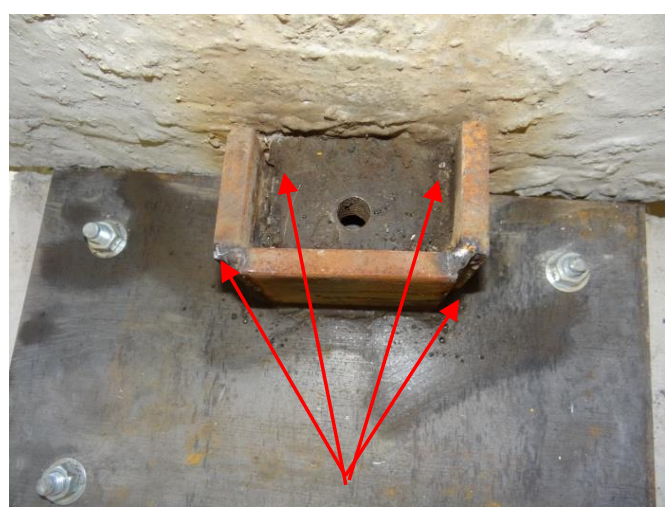

Cordão de solda

(b)

Figura 2: (a) Fixação do painel na simulação de laje de concreto e (b) detalhe das soldas

\section{PROGRAMA EXPERIMENTAL}

O programa experimental contemplou a avaliação quanto ao desempenho estrutural da fachada (painel e fixação), com atenção especial ao comportamento do sistema de fixação do painel à laje de concreto armado, envolvendo o uso de insertos metálicos soldados. O desempenho estrutural da fachada contempla o Estado Limite de Serviço (ELS) e no Estado Limite Último (ELU), conforme estabelece a ABNT NBR 15575-4:2013 e a Diretriz SINAT 001/03:2017.

Para realizar os ensaios de compressão centrada e compressão excêntrica foi verificada a carga de vento preconizada conforme estabelece a ABNT NBR 15575:2013, que seria equivalente a uma pressão de $138,06 \mathrm{~kg} / \mathrm{m}^{2}$ ou aproximadamente $1,4 \mathrm{kN} / \mathrm{m}^{2}$. Posteriormente fez-se o cálculo do momento fletor utilizando a pressão dinâmica de $1,4 \mathrm{kN} / \mathrm{m}^{2}$ multiplicada pela largura do corpo de prova de 0,5 metros, obtendo-se uma carga contínua de $0,7 \mathrm{kN} / \mathrm{m}$.

Para determinar a carga pontual equivalente à carga distribuída do vento para os ensaios foi efetuada uma comparação entre os momentos fletores gerados pela carga distribuída e pela carga pontual equivalente, no corpo de prova, conforme é apresentado na Figura 3. 


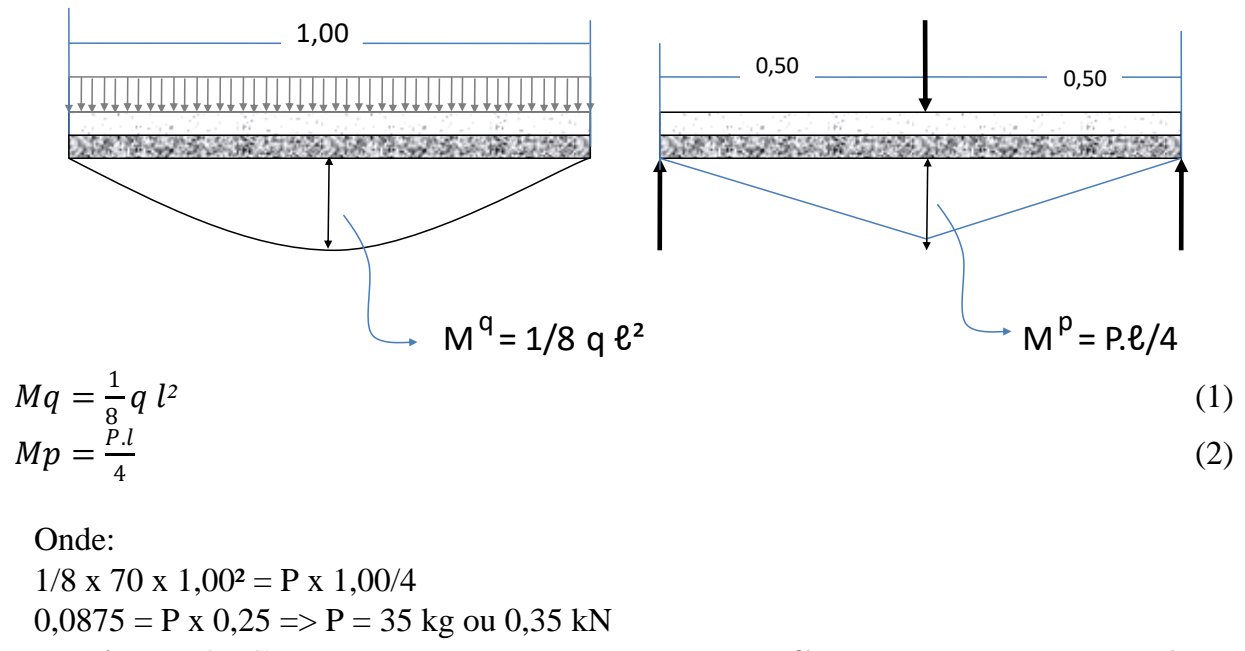

Figura 3: Comparação entre os momentos fletores e carga pontual

Considerando o peso próprio do corpo de prova que é de $1,2 \mathrm{kN}$ e a carga de vento encontrada para o corpo de prova $(0,35 \mathrm{kN})$ a ação do vento é aproximadamente $30 \%$ do peso próprio do corpo de prova. Outro dado importante é a pressão pressão externa máxima de $1,5 \mathrm{kPa}(+3,3 \mathrm{kPa}$ com estimativa para 50 anos), totalizando uma pressão de $4,8 \mathrm{kPa}$ ou $4,8 \mathrm{kN} / \mathrm{m}^{2}$, e uma pressão externa mínima de - 3,5kPa $\left(-1,5 \mathrm{kPa}\right.$ com estimativa para 50 anos), totalizando $-5,0 \mathrm{kPa}$ ou $-5 \mathrm{kN} / \mathrm{m}^{2}$.

Tomando a pressão externa máxima de $4,8 \mathrm{kN} / \mathrm{m}^{2}$, multiplicada pela largura do corpo de prova $(0,5 \mathrm{~m})$, chega-se a uma carga distribuída de $2,4 \mathrm{kN} / \mathrm{m}$, que tem efeito equivalente, em termos de momentos, a uma carga pontual de $1,2 \mathrm{kN}$. Nos ensaios de compressão centrada e excêntrica, a ação do vento foi desconsiderada, pois o intuito era avaliar o Estado de Limite de Serviço e Estado Limite Último somente sob ação de carregamento vertical. O Quadro 1 apresenta as premissas de ensaios.

Quadro 1. Premissas de ensaios para o Estalo Limite de Serviço e o Estado Limite Último.

\begin{tabular}{|c|c|c|c|c|}
\hline \multirow[b]{2}{*}{ Descrição } & & \multicolumn{2}{|c|}{ Dimensões } & \multirow[t]{2}{*}{ Considerações } \\
\hline & Quant & $\begin{array}{c}\text { Altura } \\
\text { (mm) }\end{array}$ & $\begin{array}{c}\text { Largura } \\
(\mathrm{mm})\end{array}$ & \\
\hline \multicolumn{5}{|c|}{ Compressão Centrada } \\
\hline $\mathrm{CP} 1$ & 01 & 1000 & 500 & \multirow{3}{*}{$\begin{array}{l}\text { Condições de fixação (laje): Viga de concreto } \\
\text { armado, representativa da laje, chapa de aço patinado } \\
(400 \times 400 \times 8) \text { mm e } 06 \text { parabolt de aço inox } 1 / 2 \text { x } \\
\text { 4", diâmetro e comprimento, respectivamente, } \\
\text { utilizados para fixar a chapa metálica na viga de } \\
\text { concreto armado. Condições de fixação (solda): } \\
\text { Solda em cordão para fixar o painel de concreto } \\
\text { armado na chapa de aço patinado. }\end{array}$} \\
\hline $\mathrm{CP} 2$ & 01 & 1000 & 500 & \\
\hline CP3 & 01 & 1000 & 500 & \\
\hline \multicolumn{5}{|c|}{ Compressão Excêntrica } \\
\hline $\mathrm{CP} 4$ & 01 & 1000 & 500 & \multirow{3}{*}{$\begin{array}{l}\text { Condições de fixação (laje): Viga de concreto } \\
\text { armado, representativa da laje, chapa de aço patinado } \\
(400 \times 400 \times 8) \mathrm{mm} \text { e } 06 \text { parabolt de aço inox } 1 / 2 \text { ” } \\
4 \text { ", diâmetro e comprimento, respectivamente, } \\
\text { utilizados para fixar a chapa metálica na viga de } \\
\text { concreto armado. Condições de fixação (solda): } \\
\text { Solda em cordão para fixar o painel de concreto } \\
\text { armado na chapa de aço patinado. }\end{array}$} \\
\hline CP5 & 01 & 1000 & 500 & \\
\hline CP6 & 01 & 1000 & 500 & \\
\hline
\end{tabular}


O procedimento de ensaio adotado para caracterizar o comportamento dos corpos de prova representativos da fachada em painel de concreto armado pré-fabricado, fixado com insertos metálicos soldados, em relação a carga centrada está delineado a seguir:

a) Colocação do painel no pórtico de carga ajustando os apoios para o Corpo de Prova ficar excêntrico, $1 \mathrm{~cm}$ de deslocamento do cento do painel.

b) Pórtico com capacidade de 65 toneladas, instrumentalizado com uma célula de carga com capacidade de 50 toneladas.

c) As leituras da célula de carga foram executadas com o auxílio de um sistema de aquisição de dados SYSTEM 8000.

d) Aplicação sucessiva de incrementos de carga de compressão, com intensidade de $50 \mathrm{kN}$, em cada etapa, até o colapso do painel.

e) Observação em cada etapa do comportamento do painel em relação a uma degradação do mesmo e sinais de perda de sua funcionalidade;

f) Finalizar o ensaio com o colapso da fixação painel e inserto metálico.

\section{RESULTADOS DOS ENSAIOS}

O Quadro 2 apresenta os resultados do ensaio do CP1, CP2 e CP3 mostrando as cargas ao qual cada os corpos de prova foi submetido e identifica as ocorrências como a $1^{\text {a }}$ fissura aparente e o colapso da fixação do painel de concreto armado pré-fabricado e o inserto metálico para cada corpo de prova. As Figuras 4, 5 e 6 apresentam as características da $1^{\text {a }}$ fissura aparente e o colapso de cada corpo de prova, Cp1, Cp2 e cp3, respectivamente.

Quadro 2. Comportamento do CP1, CP2 e CP3 em relação a carga excêntrica.

\begin{tabular}{c|c}
\multicolumn{2}{c}{ CP1 } \\
\hline $\begin{array}{c}\text { Carga } \\
(\mathbf{k N})\end{array}$ & Observações \\
\hline 0 & Nenhuma Ocorrência \\
\hline 50 & Nenhuma Ocorrência \\
\hline 100 & Nenhuma Ocorrência \\
\hline 150 & Nenhuma Ocorrência \\
\hline 200 & Nenhuma Ocorrência \\
\hline 250 & Nenhuma Ocorrência \\
\hline 274 & $\begin{array}{c}1^{\text {a }} \text { Fissura, conforme } \\
\text { Figura 4.1(a). }\end{array}$ \\
\hline 283 & $\begin{array}{c}\text { Colapso da fixação } \\
\text { painel e inserto } \\
\text { metálico, com ruptura } \\
\text { da solda, conforme } \\
\text { Figura 4.1 (b). }\end{array}$ \\
\hline
\end{tabular}

CP2

\begin{tabular}{ll}
\hline $\begin{array}{l}\text { Carga } \\
(\mathbf{k N})\end{array}$ & Observações \\
\hline 0 & Nenhuma Ocorrência \\
\hline 50 & Nenhuma Ocorrência \\
\hline 100 & Nenhuma Ocorrência \\
\hline 150 & Nenhuma Ocorrência \\
\hline 200 & Nenhuma Ocorrência \\
\hline 243 & $\begin{array}{l}1^{\text {a }} \text { Fissura, conforme } \\
\text { Figura 4.2(a) }\end{array}$ \\
\hline 256 & $\begin{array}{l}\text { Colapso da fixação } \\
\text { painel e inserto } \\
\text { metálico, com } \\
\text { ruptura da solda, } \\
\text { conforme Figura } \\
\text { 4.2(b) }\end{array}$ \\
\hline
\end{tabular}

CP3

\begin{tabular}{c|c}
\hline $\begin{array}{c}\text { Carga } \\
\text { (kN) }\end{array}$ & Observações \\
\hline 0 & Nenhuma Ocorrência \\
\hline 50 & Nenhuma Ocorrência \\
\hline 100 & Nenhuma Ocorrência \\
\hline 150 & Nenhuma Ocorrência \\
\hline 177 & Nenhuma Ocorrência \\
\hline 200 & Nenhuma Ocorrência. \\
\hline 208 & $\begin{array}{c}1^{\text {a }} \text { Fissura, conforme } \\
\text { Figura 4.3(a). }\end{array}$ \\
\hline 222 & $\begin{array}{c}\text { Colapso da fixação } \\
\text { painel e inserto } \\
\text { metálico, com ruptura } \\
\text { da solda, conforme } \\
\text { Figura 4.3(b). }\end{array}$ \\
\hline
\end{tabular}

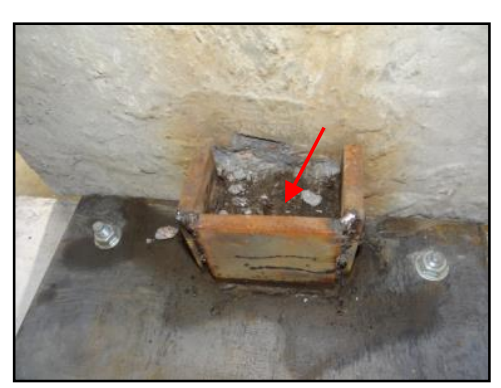

(a)

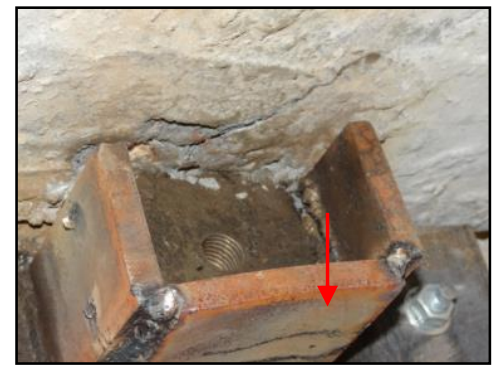

(b)

Figura 4. Ensaio de carga centrada CP1: (a) detalhe da $1^{\text {a }}$ fissura, com carga de $274 \mathrm{kN}$, e (b) detalhe do colapso da fixação painel e inserto metálico, com carga de $283 \mathrm{kN}$. 


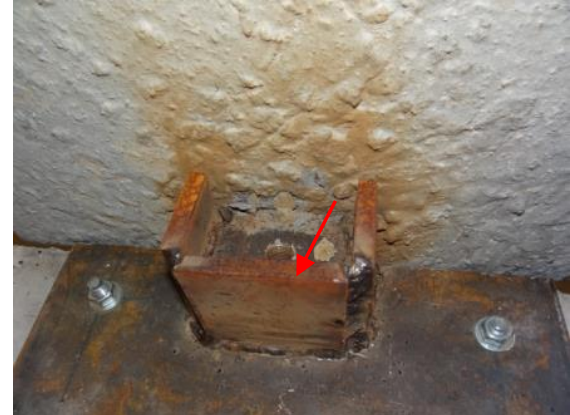

(a)

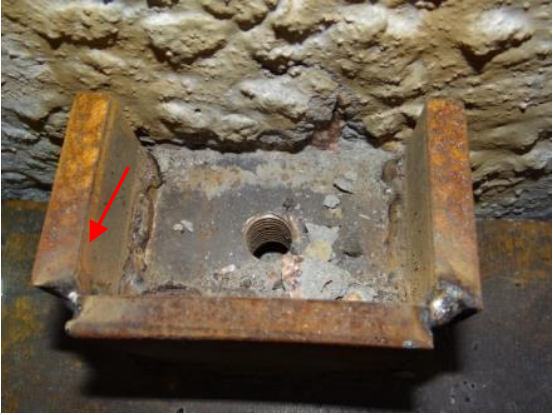

(b)

Figura 5. Ensaio de carga centrada CP2: (a) detalhe da $1^{\text {a }}$ fissura, com carga de $243 \mathrm{kN}$, e (b) detalhe do colapso da fixação painel e inserto metálico, com carga de $256 \mathrm{kN}$.

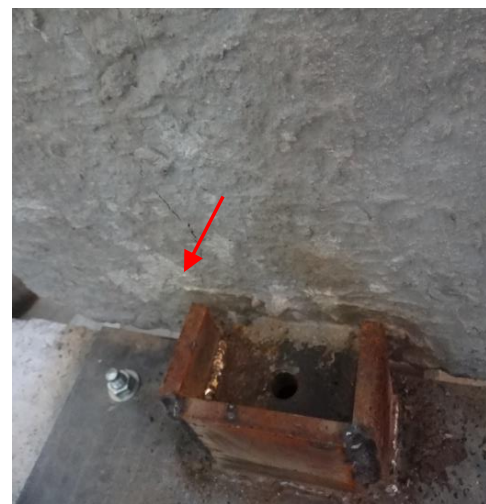

(a)

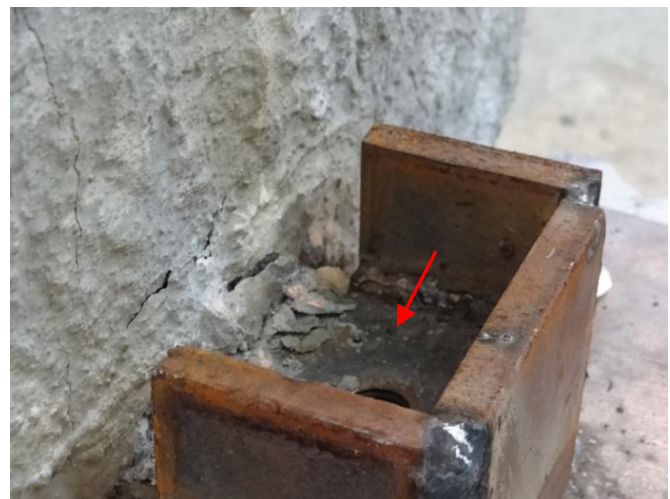

(b)

Figura 6 - Ensaio de carga centrada CP3: (a) detalhe da $1^{\text {a }}$ fissura, com carga de $208 \mathrm{kN}$, e (b) detalhe do colapso da fixação painel e inserto metálico, com carga de $222 \mathrm{kN}$.

Referente ao ensaio do CP1, observa-se que com a carga de $274 \mathrm{kN}$ ocorreu a primeira fissura no painel de concreto e com a carga de $283 \mathrm{kN}$ ocorreu o colapso da fixação entre painel e inserto metálico com a ruptura da solda; o CP2 apresenta que a primeira fissura ocorreu com uma carga de $243 \mathrm{kN}$ e o colapso da fixação entre o painel e inserto metálico com a ruptura da solda ocorreu com a carga de $256 \mathrm{kN}$.

Em relação ao CP3 a primeira fissura ocorreu com uma carga de $208 \mathrm{kN}$ e o colapso da fixação entre o painel e inserto metálico com a ruptura da solda ocorreu com a carga de $222 \mathrm{kN}$. Com os resultados foi possível identificar o Estado Limite de Serviço (ELS) e o Estado Limite Último (ELU) da fixação painel e inserto metálico, conforme pode ser observado no Quadro 3.

Quadro 3. Estado Limite de Serviço (ELS) e Estado Limite Último (ELU) dos CP1, CP2 e CP3 quando submetidos à carga centrada $(\mathrm{kN})$ com inserto metálico.

\begin{tabular}{|c|c|c|c|c|}
\hline $\begin{array}{c}\text { Corpo de } \\
\text { Prova }\end{array}$ & $\begin{array}{c}\text { Comprimento } \\
\text { painel (m) }\end{array}$ & $\begin{array}{c}\text { Carga } \\
(\mathbf{k N})\end{array}$ & Carga / metro & Estado Limite \\
\hline \multirow{2}{*}{$\mathrm{CP} 1$} & \multirow{2}{*}{0,50} & 274 & 548 & Serviço \\
\cline { 3 - 5 } & \multirow{2}{*}{$\mathrm{CP} 2$} & 283 & 566 & Último \\
\hline \multirow{2}{*}{$\mathrm{N} 3$} & 0,50 & 243 & 486 & Serviço \\
\cline { 3 - 5 } & \multirow{2}{*}{0,50} & 256 & 512 & Último \\
\cline { 3 - 5 } & & 208 & 416 & Serviço \\
\hline
\end{tabular}


Para o CP1 ficou caracterizado o Estado Limite de Serviço (ELS) com a carga de $274 \mathrm{kN}$, onde se obtém uma carga de serviço de $548 \mathrm{kN} / \mathrm{m}$, considerando o comprimento do painel de 0,50m. E o Estado Limite Último (ELU) foi caracterizado com uma carga de $283 \mathrm{kN}$, onde se obtém uma carga última de $566 \mathrm{kN} / \mathrm{m}$, considerando o comprimento do painel de $0,50 \mathrm{~m}$.

Para o CP2 ficou caracterizado o Estado Limite de Serviço (ELS) com a carga de $243 \mathrm{kN}$, onde se obtém uma carga de serviço de $486 \mathrm{kN} / \mathrm{m}$, considerando o comprimento do painel de $0,50 \mathrm{~m}$. E o Estado Limite Último (ELU) foi caracterizado com uma carga de $256 \mathrm{kN}$, onde se obtém uma carga última de $512 \mathrm{kN} / \mathrm{m}$, considerando o comprimento do painel de $0,50 \mathrm{~m}$.

Para o CP3 ficou caracterizado o Estado Limite de Serviço (ELS) com a carga de 208kN, onde se obtém uma carga de serviço de $416 \mathrm{kN} / \mathrm{m}$, considerando o comprimento do painel de 0,50m. E o Estado Limite Último foi caracterizado com uma carga de $222 \mathrm{kN}$, onde se obtém uma carga última de $444 \mathrm{kN} / \mathrm{m}$, considerando o comprimento do painel de $0,50 \mathrm{~m}$.

\section{CONSIDERAÇÕES SOBRE OS PAINÉIS EM ESCALA REAL E OS CORPOS DE PROVA ENSAIADOS}

Os painéis de concreto armado utilizados na obra da OAS Empreendimentos S.A. na cidade de Porto Alegre, RS, têm pesos próprios diversos. Segundo a Merit \& Deboni Sistemas Construtivos S.A, fornecedora dos painéis de concreto armado, o painel de maior peso próprio tem 4,5 toneladas e é utilizado apenas no térreo, fixado com (3) três insertos metálicos na parte inferior e (4) quatro insertos metálicos na parte superior. O painel de maior peso próprio fixado em todos os andares da obra tem 3,25 toneladas, fixado com dois insertos metálicos na parte inferior e dois insertos metálicos na parte superior, como é apresentado no desenho esquemático da Figura 7.

Para análise, considerou-se a pior situação para fixação, ou seja, a fixação dos painéis apenas nos insertos metálicos inferiores. Para o painel de 4,5 toneladas o peso próprio foi dividido por 3 (três), onde cada inserto metálico tem uma carga de 1,5 toneladas ou $15 \mathrm{kN}$. Para o painel de 3,25 toneladas o peso próprio foi divido por 2 (dois), onde cada inserto metálico tem uma carga de 1,625 toneladas ou $16,25 \mathrm{kN}$.

Ao considerarmos os resultados da tabela 4.4, percebe-se que a menor carga de serviço foi de $208 \mathrm{kN}$ para o CP3, por inserto metálico, e a menor carga última foi de $222 \mathrm{kN}$ para o CP3, por inserto metálico. As cargas resultantes do ensaio experimental indicam que a fixação entre painel e inserto metálico comporta cargas muito superiores ao peso próprio dos maiores painéis utilizados na obra da OAS Empreendimentos S.A.

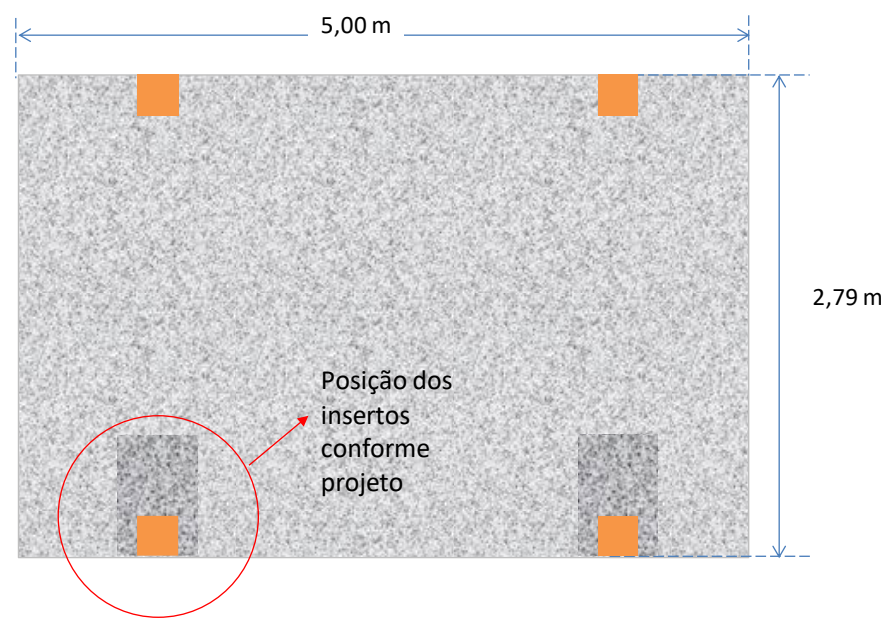

Figura 7 - Desenho esquemático do painel de 3,25 toneladas, com dois insertos metálicos na parte inferior e dois na parte superior. 


\section{CONCLUSÕES}

Este trabalho teve como foco avaliar o desempenho de sistemas construtivos de paredes de concreto armado moldadas na local frente as exigências da Diretriz SINAT no 001/02 e da ABNT NBR 15575 com o objetivo de avaliar a isenção de ensaios para os requisitos de segurança estrutural. Houve a necessidade de realizar três ensaios para a adequação entre o sistema e o dispositivo de fixação, a fim de obter o resultado adequado aos limites estabelecidos e a conlcusão é que tipo de fixação utilizado para compor o Sistema de Vedação Vertical Externo, SVVE, (fachadas), sem função estrutural, suportam cargas superiores ao peso próprio do painel.

\section{REFERÊNCIAS}

Associação Brasileira de Normas Técnicas (2012). NBR 15.575:Edificações Habitacionais Desempenho. Rio de Janeiro.

Associação Brasileira de Normas Técnicas (2011). NBR 16.055:Parede de concreto moldada no local para a construção de edificações - Requisitos e procedimentos. Rio de Janeiro.

Lorenzi, L. S. (2013), Análise Crítica e Proposições de Avanço nas Metodologias de Ensaios Experimentais de Desempenho à luz da ABNT NBR 15575 para Edificações Habitacionais de Interesse Social Térreas. 2013. 222p. Tese (Doutorado) - Programa de Pós graduação em Engenharia Civil, Universidade Federal do Rio Grande do Sul. Porto Alegre, 2013

Ministério das Cidades - Secretaria Nacional da Habitação (2017). Diretriz SINAT no001/03. Diretriz para Avaliação Técnica de sistemas construtivos em paredes de concreto armado moldadas no local. Silva, M. A. C. (2011), Desafios da Aplicação Prática do Conceito de Desempenho e seu Impacto na Qualidade das construções. In: $4^{\circ}$ Seminário de Patologia das Construções, UNISINOS, 2011. 